\title{
O papel da gestão escolar na construção de uma educação
}

pública de qualidade socialmente referenciada

The role of school management in building a quality education socially referenced

\author{
El papel de la gestión escolar en la construcción \\ de una educación pública de calidad referenciada socialmente
}

\author{
Camila Grimes \\ Universidade Regional de Blumenau (Furb), Blumenau/SC - Brasil \\ Secretaria de Estado da Educação de Santa Catarina (Sedsc) - Major Gercino/SC - Brasil \\ Rozane Fermino \\ Secretaria de Estado da Educação de Santa Catarina (Sedsc) - Major Gercino/SC - Brasil \\ Flávio Booz \\ Secretaria de Estado da Educação de Santa Catarina (Sedsc) - Major Gercino/SC - Brasil \\ Andrea Stefania Piazza \\ Secretaria de Estado da Educação de Santa Catarina (Sedsc) - Major Gercino/SC - Brasil
}

\begin{abstract}
Resumo
A gestão escolar na E.E.B. Manoel Vicente Gomes, em Major Gercino - SC, ainda está em processo de desenvolvimento, visto que vem sendo vivenciada ao longo dos últimos quatro anos por toda comunidade escolar. Desse modo, o objetivo geral desta investigação é analisar o papel da gestão escolar na construção de uma educação de qualidade, socialmente referenciada na rede pública estadual de Santa Catarina, por meio dos posicionamentos de gestores, professores e estudantes. A pesquisa possui uma abordagem metodológica qualitativa e perspectiva etnográfica, além de utilizar como instrumentos de geração de dados os diários reflexivos. O desenvolvimento de uma educação de qualidade socialmente referenciada na escola aconteceu valorizando a capacidade do corpo discente e docente, promovendo, assim, o trabalho pedagógico de forma integrada e colaborativa, visando à construção do conhecimento.
\end{abstract}

Palavras-chave: Gestão escolar, Educação básica, Rede estadual.

\begin{abstract}
School management at E.E.B. Manoel Vicente Gomes in Major Gercino - Santa Catarina state is still in process of development since the entire school community has been experienced it over the last four years. The general objective of this research is to analyze the role of school management in the construction of quality education in public State Educational System of Santa Catarina, through the perceptions of school managers, teachers, and students. The research has a qualitative methodology and ethnographic perspective. The data were generated through reflective diaries. The development of a quality education socially referenced in the school happened recognizing the value of student and teacher capacity in promoting pedagogical work in an integrated and collaborative way aiming the construction of knowledge.
\end{abstract}

Keywords: School management, Basic education, State school

Revista Educação Online, Rio de Janeiro, n. 36, jan-abr 2021, p. 52-69 


\section{Resumen}

La gestión escolar en E.E.B. Manoel Vicente Gomes, en Major Gercino - SC, aún se encuentra en proceso de desarrollo, como lo ha experimentado durante los últimos cuatro años toda la comunidad escolar. Así, el objetivo general de esta investigación es analizar el papel de la gestión escolar en la construcción de una educación de calidad referenciada socialmente en la red pública estatal de Santa Catarina, a través de los posicionamientos de directivos, docentes y estudiantes. La investigación tiene un enfoque metodológico cualitativo y una perspectiva etnográfica, además de utilizar diarios reflexivos como instrumentos de generación de datos. El desarrollo de una educación de calidad referenciada socialmente en la escuela se llevó a cabo valorando la capacidad del alumnado y del profesorado, promoviendo así el trabajo pedagógico de forma integrada y colaborativa, apuntando a la construcción del conocimiento.

Palabras clave: Gestión escolar, Educación básica, Red estatal

\section{Introdução}

Os professores e a gestão são tão importante que nos ensinam ao ponto de conquistar um futuro. Na escola aprendemos também a amar pois nos tornamos uma família. A família Manoel. (Diário Reflexivo. Estudante 03 - 2019/2)

A Escola de Educação Básica Manoel Vicente Gomes da rede pública do estado de Santa Catarina se localiza em Major Gercino. Atualmente, a escola atende aproximadamente a 156 estudantes, distribuídos entre o $6^{\circ}$ e $9^{\circ}$ anos do ensino fundamental e da $1^{\underline{a}}$ à $3^{\underline{a}}$ série do ensino médio.

A liderança e o comprometimento da gestão com a sua função é fundamental para a construção de uma gestão escolar que vise à construção de uma educação de qualidade socialmente referenciada. Nesse sentido, Lück (2012) reflete que a equipe de gestão escolar precisa desempenhar sua função de liderança e comprometimento, reconhecendo o trabalho pedagógico, influenciando positivamente os envolvidos, para que, coletivamente, aprendam, construam conhecimento, desenvolvam competências, realizem projetos, promovam melhorias, assim desenvolvendo a inteligência social e emocional da comunidade escolar.

A gestão escolar na E.E.B. Manoel Vicente Gomes ainda está em processo de desenvolvimento, visto que vem sendo vivenciada ao longo dos últimos quatro anos por toda comunidade escolar, desde quando a atual gestão eleita pela comunidade escolar assumiu a escola, no ano de 2016. 
A Secretaria de Estado da Educação - SED fortalece a gestão democrática e os processos de participação da comunidade escolar e das instâncias colegiadas, desde 2014, instituindo a possibilidade da escolha do seu gestor, por meio da análise de propostas de Plano de Gestão Escolar - PGE, apresentadas por profissionais da educação, interessados em ocupar a função de diretor de Unidade Escolar. O PGE explicita metas, objetivos e ações, que destacam o compromisso com o acesso, a permanência, a inclusão, o percurso formativo com êxito nos processos de ensinar e de aprender, na perspectiva da formação integral dos estudantes (SANTA CATARINA, 2019).

A gestão dessa escola possuía como objetivo, quando lançou seu Plano de Gestão Escolar, na eleição de 2016, desenvolver os princípios da gestão democrática, junto ao corpo docente, discente, administrativo, pedagógico, comunidade e órgãos do poder público, bem como um trabalho efetivo de resgate do papel social e político da escola frente aos vários fatores intrínsecos e extrínsecos da comunidade que comprometem a dignidade, a responsabilidade social e a cidadania dos atores envolvidos. Além disso, promover a construção do conhecimento e o desenvolvimento pedagógico, com uma educação de qualidade socialmente referenciada, junto à comunidade escolar, possibilitando que o educando tenha uma aprendizagem significativa e possa assumir a responsabilidade de ser agente transformador social e contribuir para a construção de uma sociedade mais igualitária (MAJOR GERCINO, 2016).

Buscando elucidar o conceito de qualidade na educação, considerando os diversos sentidos e interpretações, Almenara e Lima (2017) definem educação de qualidade socialmente referenciada como um conjunto de relações historicamente construídas pelos sujeitos que compõem os espaços educacionais, por meio da dialogia inerente aos contextos sociais.

Ao encontro desse pensamento, Silva (2009) delimita quatro fatores, o socioeconômico, o sociocultural, o financiamento e o compromisso dos gestores, como referências para a qualidade da educação escolar. Ainda, aponta a existência de outros componentes dentro organização para definir a qualidade socialmente referenciada. Percebemos não só a temporalidade do conceito, como também uma demanda de criticidade nos fazeres da gestão escolar, no sentido de acompanhar as construções sociais de qualidade na educação. 
Desse modo, o objetivo geral desta investigação é analisar o papel da gestão escolar na construção de uma educação de qualidade socialmente referenciada, na rede pública estadual de Santa Catarina, por meio dos posicionamentos de gestores, professores e estudantes.

Na sequência, apresentamos os pressupostos metodológicos que deram suporte a presente investigação.

\section{Pressupostos metodológicos}

A pesquisa possui uma abordagem metodológica qualitativa. Os estudos qualitativos têm como abrangência a valoração da prática educativa, tendo a emancipação dos sujeitos como principal objetivo (ESTEBAN, 2010). Nesse sentido, a perspectiva etnográfica é um método de encaminhamento e análise desta pesquisa, que permite uma compreensão mais detalhada e aprofundada dos contextos e dos sujeitos envolvidos na investigação (FRITZEN, 2012).

Os diários reflexivos desenvolvidos pelos gestores, professores e estudantes da escola, durante o processo de desenvolvimento de uma educação de qualidade socialmente referenciada na unidade escolar, foram utilizados para a geração de dados nesta investigação. O diário reflexivo é um gênero discursivo utilizado como instrumento para registrar as atividades e reflexões realizadas em sala de aula ou no ambiente escolar (COLAÇO, 2015). A escrita original dos sujeitos foi mantida nos excertos.

Os diários reflexivos foram propostos no ano de 2019, de forma voluntária, pelos pesquisadores, aos sujeitos participantes do estudo, redigidos em cadernos de forma individual, respeitando os aspectos éticos. A geração de dados e a sistematização desse material aconteceram por meio da leitura dos diários e seleção de regularidades relacionadas ao objetivo da pesquisa.

Na sequência, analisaremos o papel da gestão escolar no processo de desenvolvimento de uma educação pública de qualidade socialmente referenciada, em uma escola estadual de Santa Catarina. 


\section{O papel da gestão escolar no processo de desenvolvimento de uma} educação pública de qualidade socialmente referenciada na E.E.B. Manoel Vicente Gomes

A gestão da unidade escolar possibilitou, desde o primeiro ano, a construção de uma escola para a comunidade, e não apenas um educandário, desenvolvendo, assim, uma proposta de a escola se tornar uma "família". Daí, surgiu o termo dentro da própria comunidade escolar "A Família Manoel", ou ainda "\#FamíliaManoel" nas redes sociais. A gestão divulga as atividades da comunidade na página do Facebook da escola. Logo, a comunidade escolar começou a nutrir um sentimento especial de pertencimento à escola, inexistentes nas gestões anteriores, adotando essa visão de família para a escola.

Os estudantes corroboram esse pensamento com as suas reflexões, conforme o posicionamento do Estudante 18: "Acho que a escola age realmente como uma família" (Estudante 18 - Diário Reflexivo. 2019/2, grifo dos autores). Também destacado na escrita do Estudante 12: "No meu antigo colégio não tinha tudo isso que tem aqui, te tratam como sua família e nós somos uma família" (Estudante 12 - Diário Reflexivo. 2019/2, grifo dos autores). Ou ainda, o pensamento do Estudante 36: "Minha sorte foi entrar no mesmo ano, em que a nova gestão escolar foi definida. Em 2016, surgiu a \#FamíliaManoel, simplificando seu nome e trazendo inúmeros benefícios à escola. Um novo lar" (Estudante 36 - Diário Reflexivo. 2019/2, grifos dos autores). Nesse contexto, o Estudante 39 ressalta:

Os professores e gestão fazem bastante diferença na minha vida, como a escola, é muito bom fazer parte da tão esperada família Manoel; aqui, assim, eu pude aprender muito mais coisas, 'se' divertir mais, ler muito mais, na Manoel, temos muito mais coisas para fazer; eu adoro de verdade a família Manoel. (Estudante 39 - Diário Reflexivo. 2019/2, grifos dos autores).

Esse sentimento de identidade familiar e de pertencimento é muito importante para a construção de um projeto de escola. A equipe gestora investiu muito em projetos de aprendizagem e atividades diferenciadas para 0 desenvolvimento do sentimento de pertença da comunidade escolar. Assim sendo, segundo Vaz e André (2016, p. 174) "a construção da identidade está intimamente ligada ao ambiente em que o sujeito está inserido, ao sentimento de pertencimento, aos hábitos, às visões e aos posicionamentos perante as situações do dia a dia". 
Por isso, os aspectos culturais, religiosos, históricos e geográficos são essenciais para que o indivíduo se sinta pertencente ou não pertencente ao ambiente escolar, construindo, dessa forma, um senso crítico diante dos acontecimentos do cotidiano. O sentimento de pertencimento direciona às relações sociais entre os indivíduos, à participação em sociedade, comunidade ou grupo cultural, bem como interfere diretamente na sua relação com o espaço físico e outros aspectos relacionados aos processos de socialização (VAZ; ANDRÉ, 2016).

$\mathrm{Na}$ E.E.B. Manoel Vicente Gomes, os estudantes foram sensibilizados com diversos projetos e atividades diferenciadas a [fim de] desenvolverem 0 sentimento de pertencimento através de suas emoções e afetividade. Além disso, os professores também corroboram essas reflexões sobre o surgimento da \#FamíliaManoel e o sentimento de pertencimento de toda a comunidade escolar, a identificação com a escola, bem como, argumentam ainda, sobre a transição entre a antiga e a atual gestão escolar, conforme o posicionamento do Docente 02:

A escola que havia era mais uma linha de produção em uma fábrica. Não havia preocupação com o trabalho, desde que os alunos e professores não tivessem conflito, estava tudo certo. A atual gestão com seu slogan de Família Manoel, reconstruiu o sentimento de pertença da comunidade para com a escola. Os pais falam da "nossa escola", se sentem parte do processo. A escola tem uma identidade e alunos, professores e pais se reconhecem nela. Nunca fui de apoiar esses recursos de marketing como o Família Manoel, mas toda a dedicação da gestão atual sensibilizou a comunidade escolar e fez com que desse certo. (Docente 02 - Diário Reflexivo. 2019/2, grifos dos autores)

Essa integração entre a família e a escola foi um ponto significativo para o desenvolvimento da educação pública de qualidade socialmente referenciada na unidade escolar. De acordo com a Gestora 01, "Para que houvesse essa integração, ações como conselhos de classe participativos e reuniões foram significativas nesse processo, sendo que, nessas oportunidades, pode-se estabelecer um diálogo entre pais e professores" (Gestora 01 - Diário Reflexivo. 2019/2, grifos dos autores). A Gestora 01 infere ainda: "O Dia da Família na Escola é outra atividade que promove a uma educação de qualidade. Além da educação inclusiva, que assume um lugar central no debate acerca da sociedade contemporânea e no papel da escola" (Gestora 01 - Diário Reflexivo. 2019/2, grifos dos autores). 
Os professores corroboram essa visão da excelente integração entre a família e a escola, conforme a escrita da Docente 04: "A gestão faz com que a escola seja um espaço onde os estudantes e seus pais encontrem suporte e desejem estar ali, a escola passou a ser aliada, e não vista como inimiga. Tudo isso reflete na aprendizagem, no compromisso com a escola" (Docente 04 - Diário Reflexivo. 2019/2, grifos dos autores). Nesse sentido, 0 Estudante 21 destaca: "Um ponto fantástico da nossa escola é que eles têm tempo para sentar e conversar com os pais e os alunos" (Estudante 21 Diário Reflexivo. 2019/2, grifo dos autores). Nessa perspectiva, o Docente 01 realiza importante reflexão:

As famílias têm participado ativamente do cotidiano escolar, nos conselhos de classe participativos, nos projetos e visitando a escola, diferente de muitas escolas onde não há esse espaço; aqui, os pais têm acesso ao que acontece, as redes sociais têm sido uma importante aliada nessa questão, também a gestão não procura isentar os pais de suas responsabilidades, sempre deixando claro qual seu papel no desenvolvimento do filho; acredito que isso tem despertado as famílias para um compromisso maior com a educação. (Docente 01 - Diário Reflexivo. 2019/2, grifos dos autores).

A escola e a família atuam diretamente na formação dos indivíduos, compartilhando funções sociais, políticas e educacionais. Ambas são responsáveis pela construção do conhecimento dos estudantes, portanto, se caracterizam como duas instituições fundamentais para desenvolver os indivíduos de forma física, intelectual, emocional e social. Assim, a união entre elas é essencial, visto que, na escola, os conteúdos curriculares são aprendidos e os conhecimentos construídos; já na família, o foco é o processo de socialização, a proteção, as condições básicas de sobrevivência, bem como o desenvolvimento social, cognitivo e afetivo do sujeito (DESSEN; POLONIA, 2007).

Os depoimentos sobre o processo de desenvolvimento de uma educação de qualidade socialmente referenciada, por meio gestão escolar na E.E.B. Manoel Vicente Gomes, são extremamente significativos. Entretanto, foi um processo complexo e desenvolvido aos poucos, ao longo do tempo. A Gestora 01 da escola reflete sobre a problemática: "No que diz respeito ao âmbito político, ocorreram transformações em todas as dimensões, e a escola, que tem como compromisso socializar o saber historicamente construído, não poderia estar alheia a todas essas mudanças" (Gestora 01 - Diário Reflexivo. 2019/2). Além 
disso, a Gestora 01 infere sobre os problemas estruturais encontrados na escola no início da gestão em 2016:

No primeiro momento, a gestão encontrou todo o prédio escolar e o ginásio de esportes em uma situação bastante crítica, apresentando vidros quebrados e paredes necessitando de manutenção de pintura; o local de práticas esportivas estava ainda pior, oferecendo riscos aos discentes, como telhas dependuradas e buracos nos assoalhos, realmente uma situação caótica. (Gestora 01 - Diário Reflexivo. 2019/2, grifos dos autores)

A gestão encontrou um grande desafio estrutural na escola, uma vez que todas as solicitações de reformas não foram atendidas. Desse modo, a comunidade escolar se uniu para a minimizar os problemas. A Gestora 02 explica como aconteceu o processo de resolução da problemática relacionada à infraestrutura escolar:

Nestes quatro anos de gestão, diversas solicitações foram realizadas ao governo referente às reformas no ambiente escolar, contudo, não se obteve sucesso; desse modo, a equipe gestora, juntamente com a Associação de Pais e Professores - APP, conseguiu minimizar os problemas mais acentuados, realizando reformas e reparos nos ambientes mais críticos, devido a diversas promoções para angariar fundos ${ }^{1}, \operatorname{com} 0$ apoio de toda a comunidade escolar. Além disso, na falta de um local adequado para desenvolver aulas práticas relacionadas com o preparo de alimentos, bem como alimentação dos docentes e demais funcionários, foi construída uma cozinha para a comunidade escolar, e logo, também foi revitalizado de forma significativa, o laboratório de ciências da natureza. (Gestora 02 - Diário Reflexivo. 2019/2, grifos dos autores)

A revitalização dos espaços escolares é primordial, já que reforça os laços de pertencimento ao ambiente escolar e permite desencadear a aproximação afetiva com o lugar, além de permitir desenvolver emoções únicas, muitas vezes desconhecidas, ao ponto de realizar mudanças de atitudes sobre fatores sociais e o ambiente (SILVA, 2018). Na E.E.B. Manoel Vicente Gomes, durante o processo de desenvolvimento da nova gestão escolar, as reformas e revitalizações dos ambientes permitiram a participação efetiva e afetiva dos estudantes e seus familiares como voluntários, propiciando o surgimento de novos sentimentos em relação ao ambiente escolar.

\footnotetext{
${ }^{1}$ Apesar de as contribuições financeiras da comunidade escolar serem um fator importante para o desenvolvimento das ações da gestão escolar, cabe ressaltar que é dever do Estado financiar a educação pública, bem como responder as solicitações da escola. A insuficiência de recursos públicos destinados à escola, revelam uma realidade da educação básica brasileira, 0 que compromete a qualidade da educação socialmente referenciada.
}

Revista Educação Online, Rio de Janeiro, n. 36, jan-abr 2021, p. 52-69 
Nesse sentido, os estudantes refletem sobre as melhorias estruturais na escola, conforme a escrita do Estudante 05: "Melhorou bastante na infraestrutura. A direção está se dedicando cada vez mais para as melhorias" (Estudante 05 - Diário Reflexivo. 2019/2, grifo dos autores). O Estudante 19 reflete sobre a gestão anterior e a nova gestão, bem como sobre uma mudança de perspectiva dos estudantes em relação a escola: "[...] A nova gestão começou reformando a escola, mudando a mente dos alunos de olhar a escola de antigamente. Hoje parece uma outra escola" (Estudante 19 - Diário Reflexivo. 2019/2, grifo dos autores). O Estudante 29 destaca as reformas e a limpeza da escola: "[...] reformaram a cozinha, o laboratório, os banheiros são limpos" (Estudante 29 - Diário Reflexivo. 2019/2, grifo dos autores).

A limpeza da escola é um ponto recorrente no discurso dos estudantes e professores, visto que "uma grande parte dos recursos arrecadados pela APP são investidos na aquisição de produtos de limpeza e higiene para os banheiros e demais espaços da escola" (Gestora 02 - Diário Reflexivo. 2019/2). Dessa forma, destacam-se os dizeres do Estudante 25: "Nessa gestão, os banheiros são limpos" (Estudante 25 - Diário Reflexivo. 2019/2, grifo dos autores), bem como os pensamentos do Docente 02: "Antes não havia norte para nosso trabalho, e o ambiente físico mostrava esse clima de descaso. O prédio reflete agora esse novo ambiente: tudo limpo, organizado e funcionando" (Docente 02 - Diário Reflexivo. 2019/2, grifos dos autores).

A satisfação dos estudantes em relação à "nova escola" é nítida na sua escrita, conforme as reflexões do Estudante 11: "A escola evoluiu muito [...], reformaram as salas, [...], reformaram o ginásio, fizeram quadra de vôlei, a gestão e os professores melhoraram a escola ficou muito boa, acho que nem uma escola particular não tem o que nós temos" (Estudante 11 - Diário Reflexivo. 2019/2, grifos dos autores). Vale destacar o sentimento positivo do estudante em relação à escola pública, inferindo que a sua escola oferece mais que uma escola particular.

Outro ponto importante na escrita do Estudante 11 está relacionado com a quadra de vôlei, pois a gestão e os professores construíram esse espaço no pátio externo da escola, para que os estudantes tivessem um espaço de lazer antes do horário de aula e durante o recreio monitorado. Nessa perspectiva, o Estudante 25 apresenta a seguinte reflexão: "Os jogos de vôlei no recreio são 
uma coisa muito boa" (Estudante 25 - Diário Reflexivo. 2019/2, grifo dos autores). O Estudante 22 escreve ainda: "No meu ponto de vista, várias coisas mudaram, foram criados projetos diferentes, foi criada a quadra de vôlei, tudo isso para os alunos, a direção tenta sempre pensar nos alunos" (Estudante 22 - Diário Reflexivo. 2019/2, grifos dos autores). O Docente 01 reforça esse pensamento:

\begin{abstract}
Além de alimentar o intelecto, a gestão sabe da importância do lazer e do esporte, assim, os estudantes sempre têm disponíveis bolas de qualidade, jogos e uma quadra de vôlei; dessa forma, eles podem se distrair em seus momentos livres, sem que fiquem apenas introspectivos em seus celulares. Isso não acontece em outras escolas, onde esse tipo de atividade fica restrita às aulas de educação física, porém, aqui, a gestão, desde que iniciou seu trabalho, já investiu nessa área. Pode parecer algo simples, mas, com isso, os estudantes se mostraram mais motivados e houve a diminuição de conflitos que ocorriam nesse espaço de tempo em que ficavam ociosos. (Docente 01 - Diário Reflexivo. 2019/2, grifos dos autores)
\end{abstract}

As melhorias no ambiente escolar são significativas para 0 desenvolvimento do sentimento de pertencimento e identidade da comunidade escolar, pois possibilitam a construção de sentidos e valores a todo momento pelos envolvidos, como é possível identificar nas escritas. Dessa forma, o contexto escolar pode desenvolver habilidades de ação e reflexão da comunidade escolar em relação as suas condutas e valores (SILVA, 2018).

A implementação da prática de ensino por meio de Projetos Interdisciplinares foi uma ação fundamental da gestão escolar atual. Para a Gestora 01: "Esta ação visa a um resgate da cultura da comunidade, o desenvolvimento da autonomia dos estudantes e aprendizagem significativa dos conceitos" (Gestora 01 - Diário Reflexivo. 2019/2, grifos dos autores). Já a Gestora 02 explica a importância da referida metodologia: "O estudante é o protagonista no processo de aprendizagem, e o docente é o mediador do conhecimento, tendo como base a realidade social e cultural da comunidade, visando a uma educação libertadora e integradora" (Gestora 02 - Diário Reflexivo. 2019/2, grifos dos autores).

Iniciativas pedagógicas diferenciadas, como o ensino por projetos interdisciplinares, se configuram como estratégias pedagógicas que dinamizam os processos de ensinar e os processos de aprender, possibilitando ao estudante desenvolver o papel de investigador, com prazer pelo ato de aprender (PACHECO, 2007). 
O projeto de leitura é muito importante para a escola, conforme destaca a Gestora 01: "Em 2017, com o auxílio do Programa Mais Educação, a biblioteca, que lembrava mais um depósito de livros, foi se transformando num local agradável e, a partir desse momento, também surgiu o projeto intitulado Leitura Viva" (Gestora 01 - Diário Reflexivo. 2019/2, grifos dos autores). Segundo a Gestora 02, esse projeto: "Transformou a realidade da escola, pois investiu em obras de literatura de interesse dos estudantes para 0 desenvolvimento de práticas de leitura literária e formação de leitores na escola, aumentando significativamente o Ideb da escola" (Gestora 02 - Diário Reflexivo. 2019/2, grifos dos autores).

O investimento em livros de interesse dos estudantes é um ponto alto do projeto, a Docente 01 reconhece o papel da gestão nesse processo: "Ainda investem na compra maciça de livros, preocupação que não havia visto, até então, em outras escolas em que trabalhei" (Docente 01 - Diário Reflexivo. 2019/2, grifo dos autores).

De acordo com a Gestora 01, nos últimos anos, "Foram desenvolvidos vários projetos de destaque na escola, especialmente, os voltados para as feiras de matemática e ciências, no qual a escola ganhou várias premiações" (Gestora 01 - Diário Reflexivo. 2019/2, grifos dos autores). Outros projetos contínuos de destaque desenvolvidos na escola são o Recital de Poesias e o Festival de Dança, conforme destaca o Estudante 36: "Novos eventos culturais surgiram como: Recital de Poesias e Festival de Dança, foram ajudando a criar mais popularidade positiva para a \#FamíliaManoel" (Estudante 16 - Diário Reflexivo. 2019/2, grifos dos autores). Nesse caminho, o Estudante 38 reflete: "Tem projetos maravilhosos que fazem com que nos desenvolvamos melhor na arte, na linguagem, conhecimento no antepassado etc." (Estudante 38 Diário Reflexivo. 2019/2, grifo dos autores).

Os estudantes enfatizam muito no seu discurso o quanto é positivo o desenvolvimento dos projetos interdisciplinares na escola, conforme os dizeres do Estudante 20: "Eu acho que a gestão escolar melhorou muito de 2016 pra cá, mais atenção para a escola e muitos projetos" (Estudante 20 - Diário Reflexivo. 2019/2, grifos dos autores). O Estudante 41 reflete nessa perspectiva: "[...] adoro fazer trabalhos em equipes e amo ainda mais as criatividades dos diretores e professores para criar projetos e trabalhos divertidos" (Estudante 
41 - Diário Reflexivo. 2019/2, grifo dos autores). O Estudante 27 acrescenta: "[...] a educação é de qualidade, tem sempre projetos educacionais e inovadores" (Estudante 27 - Diário Reflexivo. 2019/2, grifo dos autores).

Os sentimentos positivos em relação a escola e os projetos são latentes: "Essa escola para mim é bem diferente das outras escolas que já vi, pelos projetos que essa escola tem. [...] De onde eu estava estudante, não havia isso tudo" (Estudante 06 - Diário Reflexivo. 2019/2, grifo dos autores). E ainda: "A gestão e os professores evoluíram, pois, a cada ano, vêm trazendo novos projetos que renovam a nossa escola e possibilitam mais aprendizado" (Estudante 16 - Diário Reflexivo. 2019/2, grifo dos autores).

O sucesso dos projetos interdisciplinares no ambiente escolar está relacionado à continuidade e ao trabalho em equipe da comunidade escolar, com organização, planejamento e avaliação. Os dizeres do Docente 02 corroboram esse pensamento: "Os projetos escolares conseguem ser contínuos, e nosso grupo conversa sobre eles, sempre apontando pontos negativos e como vamos melhorar nas próximas etapas" (Docente 02 - Diário Reflexivo. 2019/2, grifos dos autores). Além disso, a atuação da gestão escolar é significativa para o desenvolvimento dos projetos, conforme aponta a reflexão da Docente 01: "A gestão dá suporte para a execução de projetos, participando do que acontece em sala de aula e ponderando esse trabalho com críticas construtivas" (Docente 01 - Diário Reflexivo. 2019/2, grifos dos autores).

Os projetos interdisciplinares promovem os processos de ensinar e aprender, desenvolvendo as relações cognitivas e sociais. Os educadores e os educandos são agentes sociais que se entendem e se respeitam como sujeitos construtores do conhecimento. Assim, o professor atua como orientador e os estudantes desenvolvem as suas capacidades de pesquisadores, ao mesmo tempo, interagem e compartilham responsabilidades e possibilidades na resolução de desafios e desenvolvimento de ações que promovam a construção coletiva do conhecimento (PACHECO, 2007).

As relações interpessoais são um grande desafio no ambiente escolar, por isso, é importante que haja mediação de conflitos, favorecendo um clima colaborativo com compromisso ético e solidário. Desse modo, segundo a Gestora 02: "A equipe gestora atua diretamente na valorização docente e demais funcionários, mediando conflitos, promovendo formações e 
acompanhando o trabalho de todos, com contribuições positivas realizadas de forma ética" (Gestora 02 - Diário Reflexivo. 2019/2, grifos dos autores). Os professores reconhecem o trabalho da equipe gestora, de acordo com o Docente 03:

A gestão da E.E.B. Manoel Vicente Gomes tem um diferencial em relação ao que já vivenciei em minha carreira docente em outras escolas. Isso se deve a um conjunto de fatores que são bem articulados no cotidiano da escola, a preocupação com o docente é um dos fatores mais latentes, a forma humana como a gestão trata o professor. (Docente 03 - Diário Reflexivo. 2019/2, grifos dos autores).

Essa valorização docente permite que os professores tenham tranquilidade para realizar a sua prática pedagógica e desenvolver o seu papel da melhor forma possível. Os estudantes reconhecem esse excelente trabalho dos professores, como escreve o Estudante 46: "Os professores são pessoas de muita competência e compromisso com nós, alunos" (Estudante 46 Diário Reflexivo. 2019/2, grifo dos autores). Ou ainda os dizeres do Estudante 23: “Os professores passam corretamente o conteúdo, fazem várias atividades de diferentes formas, com seminários, apresentações, relatórios e debates" (Estudante 23 - Diário Reflexivo. 2019/2, grifo dos autores). E do Estudante 48: "Nestes últimos quatro anos, as mudanças para melhor foram notáveis [...]. Os professores, esforçados, didáticos. Inovam em todas as aulas" (Estudante 48 - Diário Reflexivo. 2019/2, grifo dos autores).

Além disso, os estudantes têm presente em seus discursos uma visão humana dos docentes, além de sua prática pedagógica, conforme a escrita do Estudante 06: "Os professores de onde eu estudava nem chegam perto dos que tem aqui. Professores que dão atenção aos alunos" (Estudante 06 - Diário Reflexivo. 2019/2, grifo dos autores). Os dizeres do Estudante 14: "Primeiro que os professores só querem nosso bem" (Estudante 14 - Diário Reflexivo. 2019/2, grifo dos autores). Ou ainda do Estudante 40: "[...] Professores ótimos, que sabemos que podemos confiar se precisar conversar" (Estudante 40 Diário Reflexivo. 2019/2, grifo dos autores). Para finalizar, o pensamento do Estudante 38: "Nessa nova escola, temos vários professores para nos ajudar [...]. Amo essa escola" (Estudante 38 - Diário Reflexivo. 2019/2, grifos dos autores). 
Nessa vertente, de acordo com Lima (2012), o docente é um profissional que está em constante transformação e formação, em um processo de construção de si mesmo e de sua relação com o outro. Dessa maneira, o professor é um sujeito histórico que pode, na sua prática docente, intervir na transformação social, pois tem como objetivo profissional a formação integral dos indivíduos. É uma atividade de extrema complexidade, para a qual se exige uma formação inicial e continuada qualificada, bem como apoio incondicional da equipe gestora e pedagógica da escola, para que o docente tenha condições de enfrentar os inúmeros desafios que o contexto educacional apresenta.

Uma gestão escolar democrática é aquela na qual se prioriza a participação do coletivo em todas as ações tomadas no âmbito da escola. A Gestora 01 destaca que: "Podemos dizer que na \#Famíliamanoel, todos os segmentos da comunidade escolar têm 'voz e vez'. A equipe gestora ouve todos os envolvidos na escola e podem dialogar e opinar, de maneira ativa, nas ações e decisões" (Gestora 01 - Diário Reflexivo. 2019/2, grifo dos autores). A Gestora 02 infere ainda que "Integrar a comunidade escolar e promover maior participação nas decisões coletivas é de suma importância, além de promover o respeito à diversidade social, cultural, econômica, política, étnica, de gênero, dentre outros" (Gestora 02 - Diário Reflexivo. 2019/2, grifos dos autores).

Os docentes refletem de forma muito positiva em relação ao trabalho da gestão escolar; o Docente 02 escreve: "A gestão mostra que uma escola pública pode ser de sucesso, fazendo o melhor com o que tem em mãos e buscando formas de angariar fundos para compra de materiais que nos auxiliam a desenvolver um melhor trabalho" (Docente 02 - Diário Reflexivo. 2019/2, grifo dos autores). Na escola, a aplicação dos recursos financeiros ocorre com transparência, de modo que a comunidade escolar possa acompanhar e participar das decisões financeiras. Nesse sentido, o Docente 04 escreve sobre o desenvolvimento da gestão democrática na escola:

A transparência com que a gestão trata as prestações de conta, os investimentos feitos é algo muito importante, sempre pedindo a opinião dos professores. Em muitas escolas, tudo ocorre a portas trancadas, e 0 professor é o último a saber, sendo que, na maioria das vezes, o docente pode ajudar com suas ideias e sabendo do que realmente é preciso para a melhoria de algo na escola, pois esse está intimamente ligado ao cotidiano da sala de aula a ao estudante. A gestão sabe disso, por isso, convoca reuniões, expõe 
suas ideias, escuta as dos professores e traça melhores caminhos, sempre buscando o bem-estar da escola, e não de um indivíduo. (Docente 04 Diário Reflexivo. 2019/2, grifos dos autores)

O trabalho da gestão também tem destaque na escrita dos estudantes, sendo recorrente no discurso deles o sentimento positivo de que a gestão escolar realiza suas ações pensando nos estudantes, conforme dizeres do Estudante 01: "Uma gestão excelentíssima que procura o bem-estar de todos" (Estudante 01 - Diário Reflexivo. 2019/2, grifo dos autores). O pensamento do Estudante 31: “[...] Todos são muito responsáveis, educados etc. Estão sempre querendo o melhor para a escola. Sempre tentando pensar em novas ideias e novos eventos" (Estudante 31 - Diário Reflexivo. 2019/2, grifo dos autores). Ou ainda a reflexão do Estudante 47: "Desde o começo que cheguei na escola Manoel Vicente Gomes, fui atendido com muita educação, respeito e bastante carinho comigo, todos fazem e cumprem seus papéis devidamente correto" (Estudante 47 - Diário Reflexivo. 2019/2, grifo dos autores).

Ao encontro desse pensamento, muitos estudantes desenvolveram um sentimento tão positivo em relação a escola, que nos seus discursos é latente o quanto eles veem sua escola como importante e única, conforme o Estudante 08: "Em comparação a outras escolas, o comprometimento é maior e melhor" (Estudante 08 - Diário Reflexivo. 2019/2, grifo dos autores). O destaque do Estudante 26: "A liberdade que essa escola dá, eu não vi na minha antiga escola" (Estudante 26 - Diário Reflexivo. 2019/2, grifo dos autores). O Estudante 42 acrescenta: "Tratam todo mundo e a todos como iguais, não tem diferença com ninguém” (Estudante 42 - Diário Reflexivo. 2019/2, grifo dos autores). E ainda: "Passei por várias escolas e nunca vi tantos professores que dão aula por terem paixão pelo que fazem, e também uma gestão com tantos projetos inovadores" (Estudante 44 - Diário Reflexivo. 2019/2, grifo dos autores).

Para finalizar, destacam-se as vozes dos nossos protagonistas da aprendizagem, os estudantes da E.E.B. Manoel Vicente Gomes, em relação ao processo de desenvolvimento de uma educação de qualidade socialmente referenciada por meio da gestão escolar. Nesse sentido, aborda o Estudante 24: "Acho que a escola está em sua melhor fase com professores excelentes e a gestão que faz inúmeras melhoras junto com a APP” (Estudante 24 - Diário 
Reflexivo. 2019/2, grifos dos autores). Para o Estudante 35: "Eles são ouvintes e sabem a hora de repreender; às vezes, parece escola particular de tanto que aprendo. Todos são atenciosos e a direção sempre tenta ajudar ao máximo, sempre ouvindo e resolvendo o problema" (Estudante 35 - Diário Reflexivo. 2019/2, grifos dos autores). E por fim, os dizeres do Estudante 43:

Diretora propondo ideias novas para fazer crescer a educação e cultura da mesma. Assessoria ajudando a construir uma nova perspectiva, mostrando que, o que um dia foi uma bagunça, virou umas das melhores escolas da região, e não só em educação, mas em vários outros quesitos também. Pontos negativos? Se existem, não vejo... (Estudante 43 - Diário Reflexivo. 2019/2, grifos dos autores)

Portanto, é primordial o desenvolvimento da gestão participativa na escola, promovendo o respeito à diversidade e à individualidade do outro, buscando a troca de experiências sociais, com o intuito de democratizar 0 sistema público de ensino. Assim sendo, Navarro (2004, p. 32) corrobora esse pensamento:

A democratização da gestão escolar implica na superação dos processos centralizados de decisão e a gestão colegiada, na qual as decisões nasçam das discussões coletivas, envolvendo todos os segmentos da escola, e orientadas pelo sentido político e pedagógico presente nessas práticas.

As descrições e reflexões apresentadas neste estudo indicam um processo de desenvolvimento de uma educação pública de qualidade, socialmente referenciada, na Escola de Educação Básica Manoel Vicente Gomes, visando a uma educação integral. Esse processo é de extrema complexidade e envolve diversos aspectos. Contudo, deve ser contínuo e requer muita dedicação e esforço dos envolvidos, conforme aborda a Gestora 01: "Há ainda muito para realizar na escola, mas muitas metas foram alcançadas devido ao esforço, dedicação, união e, especialmente, o compromisso de todos para fazer da \#famíliamanoel, uma escola pública e de qualidade" (Gestora 01 - Diário Reflexivo. 2019/2, grifo dos autores). A área da educação é de extrema complexidade, pois demanda um trabalho em equipe, liderado por um gestor que propicie a coliderança e a participação ativa da comunidade escolar. 


\section{Considerações Finais}

Quando eu sair dessa escola, eles podem saber que vão ficar sempre no meu coração, que se eu me formar, vou lembrar de tudo que o que cada um fez para mim. (Estudante 13 - Diário Reflexivo. 2019/2)

Os processos de ensinar e de aprender na escola estão relacionados aos aspectos sociais, históricos e culturais, diretamente ligados à construção de atitudes e valores. Nessa perspectiva, a compreensão do papel social, político e democrático da escola por todos os envolvidos é fundamental para a formação de estudantes críticos, participativos, éticos e solidários, isto é, atuando na sociedade e transformando a sua realidade.

O papel da gestão escolar no desenvolvimento de uma educação pública de qualidade, socialmente referenciada, na E.E.B. Manoel Vicente Gomes, acontece valorizando o potencial do corpo discente e docente, promovendo, assim, o trabalho pedagógico de forma integrada e colaborativa, visando à construção do conhecimento e aprendizagem significativa.

Neste estudo, compreendemos que o papel da gestão escolar está diretamente relacionado à qualidade socialmente referenciada de ensino e ao desenvolvimento do sujeito atuante na sociedade. Uma gestão participativa proporciona o diálogo, a interação social, a construção do conhecimento, a participação dos pais e responsáveis, a autonomia dos estudantes, o aperfeiçoamento docente, o respeito à diversidade e à cultura, ações colaborativas, ou seja, fortalecendo a tríade comunidade escolar, equipe unida e aprendizagem.

\section{Referências bibliográficas}

ALMENARA, G. R. V.; LIMA, P. G. A qualidade socialmente referenciada e a gestão democrática. Ensaios Pedagógicos, Sorocaba, v. 1, n. 1, p. 39-46, jan./abr. 2017

BRASIL. LDB - Lei no 9394/96, de 20 de dezembro de 1996. Estabelece as diretrizes e bases da Educação Nacional. Brasília: MEC, 1996.

COLAÇO, S. F. A travessia do ser aluno para o ser professor: práticas de letramento pedagógico no PIBID. 2015. Tese (Doutorado em Letras) Programa de Pós-graduação em Letras, Universidade Católica de Pelotas, Ucpel, Pelotas, 2015. 
DESSEN, M. A.; POLONIA, A. da C. A família e a escola como contextos de desenvolvimento humano. Paidéia, Ribeirão Preto, v. 17, n. 36, p. 21-32, 2007.

ESTEBAN, M. P. S. Pesquisa qualitativa em educação: fundamentos e tradições. Porto Alegre, AMGH, 2010.

FRITZEN, M. P. O olhar da etnografia no fazer pesquisa qualitativa: algumas reflexões teórico-metodológicas. In: FRITZEN, M. P.; LUCENA, M. I. P. (Orgs.). O olhar da etnografia em contextos educacionais: interpretando práticas de linguagem. Blumenau, SC: Edifurb, 2012. p. 55-71.

LIMA, V. M. M. A complexidade da docência nos anos iniciais na escola pública. Nuances: estudos sobre educação, Presidente Prudente, ano 18, v. 22, n. 23. p. 151-170, mai./ago. 2012.

LÜCK, H. Liderança em gestão escolar. 8 ed. Petrópolis - RJ: Vozes, 2012. MAJOR GERCINO. Plano de Gestão da Comunidade Escolar da E. E. B. Manoel Vicente Gomes: em busca de uma educação de qualidade. Major Gercino: Secretaria de Estado da Educação do Estado de Santa Catarina, 2016.

\section{MAJOR GERCINO. Projeto Político Pedagógico da Escola de Educação} Básica Manoel Vicente Gomes. Major Gercino: Secretaria de Estado da Educação do Estado de Santa Catarina, 2019.

NAVARRO, I. P. et. al. Conselho escolar, gestão democrática da educação e escolha do diretor. Brasília: MEC-SEB, 2004.

PACHECO, R. A. Ensinar aprendendo: a práxis pedagógica do ensino por projetos no ensino fundamental. Percursos, Florianópolis, v. 8, n. 2, p. 19-40, 2007.

SANTA CATARINA. Gestão escolar. Florianópolis: Secretaria de Estado da Educação do Estado de Santa Catarina. 2019. Disponível em: $<$ http://www.sed.sc.gov.br/servicos/professores-e-gestores/29052-planogestao-escolar-3>. Acesso em: 20 dez. 2019.

SILVA, A. S. Sentimentos de pertencimento e identidade no ambiente escolar. Revista Brasileira de Educação em Geografia, Campinas, v. 8, n. 16, p. 130141, jul./dez., 2018.

SILVA, M. A. da. Qualidade social da educação pública: algumas aproximações. Cad. CEDES, Campinas, v. 29, n. 78, p. 216-226, ago. 2009.

VAZ, A.C.; ANDRÉ, B. P. O sentimento de pertencimento de alunos do bairro da rasa em armação dos Búzios/RJ. Inter Science Place, v. 11, n. 4, p. 170-194, 2016. 